\title{
The Eclectic Approach to Language Teaching: Its Conceptialisation and Misconceptions
}

\author{
Dr. David Sani Mwanza
}

The University of Zambia

\begin{abstract}
The eclectic approach to language teaching has become common and fashionable in modern language teaching. However, not much has been done to explain what eclecticism is in the context of language teaching. Thus, this paper sets to explain two sides of the argument. Firstly, it argues for what the eclectic approach is (conceptions) and secondly, the commonly held misconceptions about the method are presented and discussed. Methodologically, the study was purely qualitative involving both primary and secondary data. Secondary data was collected through reading of literature on the eclectic approach. Primary data was collected through focus group discussions with 90 secondary school teachers of English who were purposively sampled from 9 secondary schools from the central province of Zambia. Part of the findings show that the eclectic approach is a hybrid which should be viewed as one method comprising features of different methods. One of the misconceptions held by some teachers was that the eclectic approach refers to the use of more than one method in a lesson one after the other.
\end{abstract}

Keywords: Eclectic Approach, Teaching, English, conceptualisation, Translanguaging, Multimodal.

\section{BACKGROUND}

The history of language teaching has been characterised by a search for more effective ways of teaching language. Although much has been done to clarify these and other important questions in language teaching, the profession is continually exploring new options for addressing these and other basic issues and the effectiveness of different instructional strategies and methods in the classroom. According to Richards and Rodgers (2001), language teaching came into its own as a profession in the twentieth century. The whole foundation of contemporary language teaching was developed during the early part of the twentieth century. Since then, a number of teaching methods and approaches have been developed.

The grammar translation method was the earliest language teaching method to be formalised and dominated language teaching from the 1840s to the 1880s. Richards and Rodgers (2001) observe that the Grammar-Translation Method is a way of studying language first through a detailed analysis of its grammar rules, followed by application of this knowledge to the task of translating sentences and texts into and out of the target language. It hence views language learning as consisting of little more than memorising rules and facts in order to understand and manipulate the morphology and syntax of the foreign language.

In terms of the classroom roles and the nature of classroom interaction, it can be stated that the roles of teachers and learners are traditional. While the teacher is the authority in the classroom, the learners do as the teacher says so that they can learn what the teacher knows. Interaction in the classroom is from the teacher to the learner. There is little student initiation and little learner-learner interaction (Qing-xue and Jin-fang 2007). Mart (2013) noted that the grammar translation method was not effective in preparing students to use the target language communicatively. Krashen (1982) explains that the method failed because learners were not able to speak the language fluently since the focus was sorely on form and not meaning. This weakness led to the development of a successive method called the direct method.

The direct method was a monolingual approach to learning a language. The method receives its name from the fact that meaning was conveyed directly in the target language through the use of demonstration and visual aids as opposed to analytical procedures that focused on explanation of grammar rules in classroom teaching. The goal of language learning was communication and learners 
needed to make a direct association between the target language and meaning. Correct pronunciation and grammar were also emphasised. Teachers therefore needed to encourage direct and spontaneous use of the foreign language in the classroom ( $\mathrm{Li} \mathrm{2012).}$

Audiolingualism was born during the mid-1940s and 1950s and was earnestly promoted by influential foreign language teaching theorists particularly in the US. Zainuddin, Yahya, Morales-Jones and Ariza (2011) note that after the direct method had been used in schools, it quickly became apparent that it had not produced people who were able to speak the foreign languages they had studied. It was for this reason that the U.S. government asked the universities to develop foreign language programs that produced students who could communicate effectively in those languages. There were changes in the beliefs about how people learn and through behavioural psychology, the audio-lingual method was born. In the audio-lingual method, the emphasis was on the memorization of a series of dialogues and the rote practice of language structures. The basic premises on which the method was based were that language is speech, not writing, and language is a set of habits. It was believed that much practice of the dialogues would develop oral language proficiency. The use of the native language was avoided. The method became very popular in the 1960s. However, the major weakness of the audio-lingual method was that learners were not able to transfer skills learnt in class to communicate meaningfully outside the classroom.

In the 1960s, the Cognitive Code approach to language teaching was born. It was a reaction against the weaknesses of the Audiolingual method. According to Skehan (1998:30) "the Cognitive Code approach enables maximum creativity in what is said. There is no constraint on the production of new combinations of meaning, since it is assumed that a rule based system is operating 'anew' for the production of each utterance and so constructions can be accomplished in total freedom". The goal was to enable the learner to use the language creatively outside the classroom. At this point, it is clearly noticeable that the development of methods was slowly moving from 'controlled' to 'greater freedom' and from teacher-centred to learner-centred methods.

When critically examining the cognitive code approach, it is clear that the focus is on rule explanation as the belief is that language is rule-governed. However, it was later observed that the method overlooked how language is used in situations. With the focus of this method, it is possible to have learners or graduates who can have good mastery of language rules but fail to use them appropriately in real life communicative situations. This criticism led to the development of the situational approach.

The Situational method was developed in the 1960s. It was a reaction to the weaknesses of the Audio lingual and the Cognitive Code approaches as it sought to present language situationally. The method involved "systematic principles of selection (the procedures by which lexical and grammatical content was chosen), gradation (principles by which the organisation and sequencing of content were determined), and presentation (techniques used for presentation and practice of items on a course" (Richards and Rodgers 2001: 38). Banda (2011) reiterates the above point when he noted that the situational approach was based on the structural syllabus (selecting, grading and orderly, presenting language forms from the harder to the simpler forms). The target language is the language of the classroom and new language points are introduced and practiced situationally. Language is learnt in the context of the culture of its people (culture being bound up in situations). In addition, the range of registers to be learnt by a learner learning an L2 should cover all aspects of life and living.

Although the situational approach was useful in presenting language as used in situations, the method overlooked other important considerations about language learning and teaching. For example, the method made an assumption that language was situational. However, language as used in real life communication cannot be predicted. In other words, one cannot predict language forms or actual utterances which can be used in a particular situation. This is so because the words, structures and sentences which a person will choose will depend on the topic, interlocutors and the culture of the people involved in a communicative event. Hence, although, the situational approach is still useful today, it has weaknesses in the way it views language use. This explains why attempts to come up with more suitable methods continued and saw the development of the Communicative language teaching approach.

The Communicative Language Teaching Approach (CLT) refers to both the processes and goals in classroom learning and the fact that communicative competence comprises abilities in expression, interpretation and negotiation of meaning (Savignon 2002). The approach arose from Dell Hymes' 
concept of 'communicative competence', and his classic utterance: "There are rules of use without which the rules of grammar would be useless" (Hymes 1972:279). This does not mean that grammar is not important, but that one has to take the whole context and communicative situation into account when determining whether an utterance is successful or not. According to Savignon (2002) and Halliday (1978), the communicative approach derives its influence from functional linguistics, in which language is viewed as central to understanding language systems and how they work.

The grammar and vocabulary taught in the classroom will follow from function, situation or context, and the different roles of the interlocutors. In terms of the roles of the teacher and the learners in the classroom, the role of the teacher is to facilitate classroom interaction by way of coming up with situations that can bring about communication. On the other hand, students need the knowledge of the linguistic forms, meaning and functions. Learners should be able to negotiate meaning in communication, know that one form can save various functions, and they must also be able to choose the most appropriate forms, given the social context (Qing-xue and Jin-fang 2007).

Although CLT has received wider acceptance and recognition than the other methods, Gebhard, Gaitan and Oprandy (1990) argue that there is no convincing evidence from pedagogic research, including research into second language instruction, that there is any universal or 'best' way to teach language. They further state that while particular approaches are likely to prove more effective in certain situations than others, a 'blanket prescription' is difficult to support theoretically.

Nunan (1991:228) is probably correct when he remarks that "it has been realised that there never was and probably will never be a method for all". Since none of the methods discussed in the section above could be used effectively in isolation from other methods, the idea of Eclecticism - a conscious blending of different methods - was developed. It must be mentioned here that in this paper, the term Eclecticism will be used synonymously to Principled Eclecticism.

\section{MOTIVATION FOR THE STUDY}

The motivation to write this paper comes from the absence or lack of literature that explains the scope of the Eclectic Method to language teaching. This is despite the method being very fashionable in modern language pedagogy. In fact, Weidemann (2006) states after the excesses of thee ALM, 'eclecticism became so widely accepted that today, many good teachers use it proudly as a tag to describe their teaching, wearing it almost as a badge of honour'. Regardless, a number of scholars (Brown, 2002; Gilliland, James and Bowman, 1994; Kumar, 2013:1; Al Hamash 1985; LarsenFreeman 2000; Mellow 2000 and Gao, 2011) have written on aspects of the Eclectic Method but none of them have written on the conceptualisation of Eclecticism as a method in its own right. The eclectic method should be viewed as a method just like CLT, Audiolingual and the Cognitive Code approach. Thus, this paper attempts to present the conceptualisation of the Eclectic Method. Further, the paper brings out some of the ways in which the Eclectic Method is misunderstood (what it is not) and by so doing, the paper clarifies how the method ought to be understood.

\section{METHODOLOGICAL ISSUES}

The study is purely qualitative and both primary and secondary data were collected to answer the questions raised in the study. Secondary data was collected through reading documents such as books, journal articles and book chapters to get what scholars have written on the eclectic approach. Different authors had written on the eclectic approach but none of them had written comprehensively on what the approach meant and how it could be realised in the classroom. Thus, through reading several writers, the secondary data was used to come up with the scope of the eclectic approach. On the other hand, Primary data was collected through focus group discussions with 90 secondary school teachers of English who were purposively sampled from 9 secondary schools in the central province of Zambia. The primary data was used mainly to answer the second part of the question (what it is not) by identifying and bringing out the misconceptions held by teachers about the eclectic approach. The data is part of a larger study on teachers' understanding and attitudes towards the eclectic approach. However, the data on their misconceptions is used to show how the eclectic approach is misunderstood and the implications it may have on teaching. In short, both secondary and primary data was collected and used. Analytically, thematic analysis was used where data was grouped according to the two identified themes and analysed qualitatively by commenting on the most salient points. 


\section{The Eclectic Approach to Language Teaching: Its Conceptualisation}

The eclectic approach was born out of the realisation that each of the individual methods had strengths and weaknesses and that no one method was responsive to the dynamic classroom context. Thus, based on the shortcoming of the methods, Brown (2002) argues that eclecticism provides the solution because the approach allows the teacher to select what works within their own dynamic contexts. Gilliland, James and Bowman (1994) stated that the justification for the eclectic approach lies in the weaknesses of the single approach because a single method has a narrow theoretical basis and has a delimited set of activities and is therefore inflexible.

\subsection{Definitions and Meaning of the Eclectic Approach}

Kumar (2013:1) notes that "the eclectic method is a combination of different method of teaching and learning approaches". It can also be viewed as principled eclecticism implying that the approach is characteristically desirable, coherent and pluralistic to language teaching. It also involves the use of a variety of language learning activities which are mostly different characteristically and may be motivated by different underlying assumptions of language teaching (Al Hamash 1985; LarsenFreeman 2000; Mellow 2000, 2002).

Gao (2011) states that principled eclecticism challenges the teacher to ensure that every decision about classroom instruction and activities is based on a thorough and holistic understanding of all learning theories and related pedagogies, in terms of the purpose and context of language teaching and learning, the needs of the learners, materials available, how language is learnt and what teaching is all. In addition, Gao (2011:1) describes the eclectic approach as "not a concrete, single method, but a method, which combines listening, speaking, reading, and writing and includes some practice in the classroom". He adds that the current preferred teaching methods are an integration of GrammarTranslation, structural method and CLT and advises teachers to take advantage of all other methods whilst avoiding their disadvantages. Wali (2009:40) summarises this proposition when he stated the following:

...one of the premises of eclecticism is that teaching should serve learners not methods. Thus, teachers should feel free in choosing techniques and procedures inside the classroom. There is no ideal approach in language learning. Each one has its merits and demerits. There is no royalty to certain methods. Teachers should know that they have the right to choose the best methods and techniques in any method according to learners' needs and learning situation. Teachers can adopt a flexible method and technique so as to achieve their goals. They may choose whatever works best at a particular time in a particular situation

To state that methods should serve learners and not methods means that teachers should focus on helping learners to learn and not on fulfilling the prescriptions of the methods. When teaching, the goal is learning and that learners should grasp the content. Cognisant that different learners learn differently and have different preferences on what factors and methods promote effective learning, the teacher should consider learner characteristics before choosing the method/s of teaching. In other words, methods should respond to the needs of the learners and not learners responding to the needs or demands of the methods. It is common knowledge that each individual method has suggestions on what learning and teaching is and how therefore, teachers should teach. The problem is that the suggestions made by individual methods are bracket prescriptions which do not consider the actual differences which exist from classroom to classroom and from one learning context to the other.

According to Weidemann (2001), the justification for the use of eclecticism as an approach to language teaching is its fashionability which is strengthened by the argument of critical pedagogy. Kumaravadivelu (2006) actually warns against relying on methods in their specifications because they do not provide all solutions to language teaching. He instead proposes a post-methodic approach to language teaching. Discussing pedagogical parameters of particularity, practicality and possibility as well pedagogic indicators of the post-method teacher and learner, she suggests that a language teacher should adopt a context-sensitive pedagogic framework which will be able to respond to special characteristics of a particular learning and teaching context. As implied above, within the framework of principled eclecticism, a teacher is not bound or confined to the prescriptions of a particular method but is free to draw from a vast range of methods and resources to teach a particular topic. In fact, 
Weidemann (2001:2) notes that the eclectic approach has been so widely accepted that "today, many good teachers use it proudly as a tag to describe their teaching, wearing it almost like a badge of honour". This means that since learners are different and have different ways of learning, it is helpful to use the eclectic approach because it strives to responds to the diversities and exigencies which normally exist in the classroom. Thus, effective teaching is about flexibility through the use of the eclectic approach.

Kumar (2013:2) actually states that "the purpose of advocating eclectic methods is to connect life experiences to the ideas presented in learning of the language. The types of learning activities teachers select are often directly related to their experiences in the real world". As mentioned above, this helps learners not to look at learning and the classroom as threats but as an extension of the home environment.

\subsection{Features of the Eclectic Approach}

It is important to note that the eclectic approach is not a rigid approach, thus, its characteristics may not be limited to the ones presented in this study. However, an attempt has been made to cover its major characteristics in as much detail as possible.

Ali (1981:7) lists the following principles of eclecticisms:

(a) Teachers are given a chance to choose different kinds of teaching techniques in each class period to reach the aims of the lesson.

(b) There is flexibility in choosing any aspect or method that teachers think suitable for teaching inside the classroom

(c) Learners can see different kinds of teaching techniques, using different kinds of teaching aids, that help to make lessons much more stimulating and ensures better understanding of the material on the other hand.

(d)Solving difficulties that may emerge from the presentation of the textbook materials

(e) Finally, it saves both time and effort in the presentation of language activities.

Since the eclectic approach is constructed by an individual teacher according to the learning and teaching context, it can also be argued that another characteristic of the approach is that it is subjective. This means that what may be called eclectic is dependent on what a particular teacher will come up with depending on the factors affecting the classroom. Teachers have the freedom to choose judiciously what works for them and decide how and what can be integrated in a particular instance to bring about learning. Thus, the subjectivity being discussed here refers to how different teachers will conceive what may constitute eclectic. However, what makes it common is the fact that the goal and basis of eclectic teaching is that learners of different characteristics should access learning without difficulties.

In addition, in the teaching and learning of English as a second language, L1 and L2 connection is inevitable. In education, the importance of learners' first language in the learning of the second language cannot be over emphasised. There are several reasons for this. Firstly, learning a new language (L2) is facilitated by what the learner already knows (L1). Hence, L1 aids L2 learning (Kumaravadivelu 2006). Stern (1992:283) noted that "it is the nature of linguistic and communicative competence that ...L1 (or the second language previously learnt) is the yardstick and guide to our new L2”. Language and culture are related.

While the recognition of first language is an important factor in the teaching and learning of a second language as part of the eclectic approach, the extent of its recognition needs clarification. In countries where English is a second language, drawing on L1 in L2 teaching and learning may be more emphasised at lower grades. However, there are less able learners in high school or senior grades who would benefit if some of the concepts in English can be explained using a local language if doing so in English is proving difficult to such learners. Some learners may also fail to express themselves or participate fully in communicative activities in class due to their deficiency in English. Instead of such learners being quiet in class, the teacher can allow them to speak by tolerating code switching and code mixing whenever they can. In the process, they can be helped by either the teacher or the learners to learn new vocabulary which would improve their communicative abilities in English. In 


\section{Dr. David Sani Mwanza}

other words, I wish to submit that the eclectic approach uses both the intralingua and the cross lingual approaches. Stern (1992:286) noted that " the emphasis on an intralingual or crosslingual strategy should be decided in relation to the goals of the learners, their previous experience in the L2, the context in which the programme takes place and the ability of the teacher to function intralingually or crosslingually". In terms of classroom application, the strategy can either be more intralingual or crosslingual depending on the factors stated above.

From the above, three characteristics of the eclectic approach have been identified. These are that eclecticism recognises the role of L1 in L2 teaching and learning, that both intralingual and crosslingual strategies are applied and that the eclectic approach is subjective. However, for all these three features to be realised, it follows that the eclectic teacher should be knowledgeable and versatile about language and language teaching.

Another characteristic is that the eclectic approach is situational or context specific. Hence, the understanding and application of the eclectic approach should be localised or contextualised to teaching and learning contexts. Naturally, the eclectic approach recognises that every teaching and learning situation is different, and therefore requires a different approach so suit the prevailing conditions. This also means that every global idea or conceptualisation of the approach should be understood and interpreted according to the local conditions of the classroom. This does not mean that global principles of language teaching are not important but that their usefulness should be appreciated context by context. Actually, Kumaravadivelu (2006:198) noted that "global principles [are] for general guidance but their implications need to be worked out for local everyday practice". In other words, while global theorising of the eclectic approach is crucial, its interpretation and application should consider the characteristics of the learners, teachers, topic, teaching and learning goals and the culture of the learners, the school and the community in which language teaching and learning occurs. This is because as Kumar (2013:2) asserts "the purpose of advocating eclectic method is to connect life experiences to the ideas presented in learning of the language. The types of learning activities teachers select are often directly related to their experiences in the real world". Thus, Alwright (2000) suggests that it is better for teachers to carry principles of language teaching from context to context than carrying principles across contexts. Commenting on the contextualisation of methods, Larsen-Freeman (2000:v) put it this way:

a method is decontextualised. How a method is implemented in the classroom is going to be affected not only by who the teacher is, but also by who the students are, their and the teachers' expectations, of appropriate social roles, the institutional constraints and demand, and factors connected to the wider socio-cultural context in which instruction takes place.

This is the reason why, as discussed above, teachers need to be well informed about the method if they are to apply it successfully. It is true that methods are decontextualised and teachers, with the knowledge of what factors surround their class, will decide how to contextualise the method so that it serves the learning needs of the learners.

The other characteristic of the eclectic approach is that error is considered as a normal part of the learning process. This does not mean that error is accepted but that error is viewed as a process of learning. Hence, error correction should not be done instantly but at the end of the communicative activity. Error correction is important as it helps learners to change their earlier knowledge which could be wrong. In grammar teaching, Curriculum Development of Zambia (2013) advises teachers to pay attention to errors in the teaching of grammar. On the importance of error correction, Krashen (1982:117) explains:

when error correction works, it does so by helping the learner change his/her conscious mental representation of a rule. In other words, it affects learned competence by informing the learner that his/her current version of a conscious rule is wrong. Thus, second language acquisition theory implies that when the goal is learning, errors should indeed be corrected.

From the above, it can be reiterated that when the goal is learning, errors should be corrected. It can be argued that without error correction, there would be no learning and there would be no need to teach because learners would still have the wrong rules and apply them in their communication even 
when they would have gone through an education system. However, it must be mentioned that error correction should not be done by the teacher alone. Learners should also be involved in correcting error as this helps them as well to test their own hypothesis of the rule they could be having. So, learner involvement should be extended to error correction of their peers. Li (2012:170) suggests that "the responsibility of error correction can be assumed by the students rather than the teacher so that they will learn from mistakes". This is so because learners also have the ability to identify mistakes made by their peers. Thus, involving them in error correction helps them develop critical thinking and a sense of being an important member of the classroom.

To exemplify the proposition in the above quote, when a learner has made a mistake during a communicative activity, the teacher may ask fellow learners to comment on the answer or contribution. Learners will state whether it is correct or not and they should be encouraged to give reasons for their opinions. At this point, the teacher assumes his/her role of a facilitator. Learning is effective and learners will enjoy the experience if they do not just learn from the teacher but from fellow learners too. This proposition is part of the conceptualisation of the eclectic approach.

Another feature of the eclectic approach is the juxtaposition of the both the inductive and the deductive strategy to teaching. Thus, the integration of the deductive and inductive strategies in the same lesson is part of the tenets of the eclectic approach especially in the teaching of English grammar. Concerning the deductive and inductive strategies, Krashen (1982) argues that both deductive and inductive teaching is important. Since learners have creative minds, they may be allowed to work out the rule themselves. However, if they are unable, the teacher should present a clear explanation about the rule to them. Thus, both of them are useful. The teacher should only know when and how to use each one of them.

The two-sided argument above is representative of the classroom reality where some learners will be able to work out the rule themselves while others will need teacher input followed by practice of the rule in order for them to master the rule or the structure being taught. It is for this reason that every well trained principled eclectic teacher will blend the two strategies in order to reach out to all the learners according to their preferred learning strategy. Hence, as Krashen (1982) advises, there is no need to insist on which one is correct and which is not. The point which Krashen is making here is that neither the deductive nor the inductive approach to rule explanation is wrong. The appropriate approach which is sensitive to the needs of all the members of the classroom is the use of both in the same lesson. This integration is also a characteristic of the eclectic approach.

Further, the eclectic approach views language as a whole. According to Larsen-Freeman (1992), the components of language such as pronunciation, grammar and vocabulary do not have meaning if used in isolation. Hence, meaning is expressed when language is used as a whole. Language teaching therefore should follow the same way. Kumar (2013) reiterates the same point when he advised that language should be viewed as a whole without separating into isolated units of pronunciation, grammar and vocabulary. As part of viewing language as a whole, language should not be separated from its culture. Hence, when teaching English as a second language, teachers ought to also focus on the cultural side of the language as it will help learners the various meanings of words according to the culture as well as what is appropriate in particular situations. Another critical point to mention is that under the eclectic approach, language is viewed as both form and function. The dichotomy means that language can be conceptualised as an overlap between language as communication and language as form. Mellow (2002:6) noted that "such intersections would acknowledge that language is both form and function, and that some active construction can occur during communicative language use...the mid-point axis is conceptualised as the pairing of form and function. Nunan (2001:193) advises teachers to teach "language in ways that make form/function relationship transparent".

It is the duality of form and function which Hymes (1972:279) had in mind when he noted "There are rules of use without which the rules of grammar would be useless". This does not mean that grammar is not important, but that one has to take the whole context and communicative situation into account when determining whether an utterance is successful or not. Similarly, one needs correct grammatical construction in order to communicate the intended meaning and avoid ambiguity. In addition, Ridge (2000) states that linguistic competence and linguistic performance are not the same thing but the two are reconcilable when teaching English in the classroom. 


\section{Dr. David Sani Mwanza}

The eclectic approach advocates for learner centred lessons. However, this does not mean that teachers should let learners do everything on their own. Gao (2011) states that a lesson should have the input stage where the teacher gives input and that it should have the practice stage where the lesson is learner centred and learners are encouraged to participate actively. He adds that the last stage is the production stage which is also learner centred and it involves learners doing an exercise or exercises based on the lesson. $\mathrm{Li}$ (2012) states that learners should practice through role play, problem solving activities, debate and group discussion. Wali (2009:36) observes that the most effective way of applying the eclectic approach is "for teachers to provide a variety of activities to meet the needs of different learning styles so that all students will have at least some activities that appeal to them...teachers need techniques that work in their particular situations with specific objectives that [are] meaningful for the kind of students they have in their classes.". Thus, what the three authors above seem to suggest is that while an eclectic lesson should be learner centred through classroom practice and written exercises, the teacher also has a duty of giving some input and guidance to the learners.

Under the eclectic approach, the role of the teacher is that of a facilitator while the role of the learners is that of active participants in the learning process. As hinted already, the role of the teacher is that of a facilitator of learning and a guide. The teacher mobilises resources and manages the classroom. $\mathrm{Li}$ (2012) states that the teacher is the organiser and guide in the learning process. During the lesson, the teacher will facilitate learning; he is the organiser of resources and the resource himself. The teacher also assesses the performance of the lesson through giving a written exercise. The teacher also gives feedback at the end of the lesson depending on the objective and content of the lesson. In addition Wali (2009) suggests that teachers should be well prepared in order for the lesson to be organised and to flow smoothly. Teachers also play an active role as directors of learning with learners as actors in the learning process. Kumaravadivelu (2006) adds that the teacher should ensure learner autonomy and ensure that the topic is socially relevant. The topic and classroom activities should be relevant to the culture of the learners. This implies that teachers should be researchers and be aware of the culture o the learners and the community. Further, the teacher should foster language awareness among learners. On the other hand, the role is that of an active participant. Li (2012:170) summarizes the roles of the learner as follows:

Learners are the centre of the class. They have multiple roles. As individuals, they are active participants of the activity, explorer of the language, negotiator and evaluator of the learning process. Their needs and interests influence the course. As a group member, the learner is the source of the input and part of a support system. Students work cooperatively in classroom activities. Their output is the others' input. They help each other in solving problems rather than depending wholly on the teacher. We can use group discussion in solving the problems so as to encourage independence. In a word, the learner takes initiative in the classroom.

\subsection{Teaching Materials}

It is important that teaching and learning materials are interesting and motivating for the learners. This means that the teacher should carefully select teaching materials according to the teaching point, leaner needs and characteristics and the cultural context of the learning and teaching context. Weidemann (2001) asserts that effective language teachers invest a lot of time collecting interesting and attractive teaching and learning materials to liven up their teaching, and never spare a thought for the learners in the process of materials development and teaching. In the eclectic approach, the teacher will use any teaching material which will be deemed fit for use. They can use realia, chats, text books, magazines, newspapers, radio, film, music, maps, pictures and computers. Both visual and linguistic materials will be used. Iedema (2003) suggest that television, film and the computer are also useful resources in communication.

Jewitt (2005) argued that in the $21^{\text {st }}$ century, image, sound and movement have entered the school classroom in new and significant ways. Duncan (2004:252) states that in the classroom, "meaning [can be] made through an interaction of music, the spoken voice, sound effects, language and pictures". This means that in terms of teaching materials, teachers should not be limited to speech; instead, they should exploit a variety of resources as long as they would be appropriate according to the learning goals. There are some materials which seem to be meant for teaching of English 
grammar. A trained teacher should be able to transform and repurpose any materials and use it anew for the objectives of the lesson at hand. This is called repurposing. Bock (2014:45) notes that semiotics are constantly being made and remade. She suggests that communicative and meaning making is a creative process in which participants can resemiotise and repurpose semiotics in order to communicate meaning in a particular context.

Hence, eclectic teachers should be creative and be able to resemiotise and using objects and materials anew depending on the topic. This means that a biology text book for example, can be used to teach English grammar. For example, the biology text books may have pictures showing processes. The teacher can use such pictures to teach presenting continuous tense by asking learners to say what is happening on the pictures with the expectation that the tense of the response will be in the present continuous tense. Consider the following example: when teaching comparison, the teacher may use the sizes of the buildings within the school to draw the structure or adjectives which will carry the suffix -er. For example, comparison may elicit sentences such as: (a) The sports hall is bigger than the staff room; (b) The junior secondary classroom block is longer than the senior secondary school classroom block. In this scenario, the buildings whose primary purpose is to accommodate learners is now being repurposed to be used and teaching materials in grammar lesson. Hence, it can be reiterated that the eclectic approach is multimodal.

\subsection{Advantages of the Eclectic Approach}

Scholars agree that there are a lot of advantages in using the eclectic approach, which opens the language teacher to a range of alternatives and embraces all the four language skills of speaking, reading, writing and listening. Further, Brown (2002) states that the eclectic approach is important because it gives the teacher freedom to choose what is appropriate in their own dynamic teaching contexts. Kumar (2013) mentions the following advantages:

(a) It is easier for learners to understand the language of the text in its cultural context

(b)It blends listening, speaking, reading and writing

(c) Helps teacher to teach effectively by drawing on the strength of various methods and avoiding their weaknesses

(d)Learning is easy due to the use of realistic situations in the classroom

The message coming from the above points is that the eclectic approach is holistic. It does not just consider the theoretical aspects of teaching and learning, but also links teaching and learning to the real life experiences of the learners while the teacher enjoys maximum freedom in using what works best in his teaching context. It also presents language holistically. As stated, it integrates all the four language skills of listening, speaking, reading and writing.

There are a lot of other advantages. For example, it is learner centred, context sensitive, live, motivating, participatory, variety of classroom activities and tasks. Learners are aware of what is expected of them. It is flexible and accommodative to the exigencies of the classroom during the lesson. In addition, it is objective correlative and produce fast results since it responds to the needs of learners of diverse characteristics (Kumar 2013).

\subsection{Disadvantages of the Eclectic Approach}

Although eclecticism is idealised as the best approach in teaching English, it is also associated with a number of disadvantages. This is ironic, considering that the eclectic approach itself is based on the weaknesses and strengths of other methods. However, this is not surprising because even the methods that existed before it were developed based on the weaknesses of the method/s that preceded them. This simply shows how complex the practice of teaching is. For example, Brown (1994:74) notes that "theoretical eclecticism is suspicious on logical and theoretical grounds [and] without principles, eclecticism is likely to fall into a state of arbitrariness". Weidemann (2001) notes the following disadvantages of the eclectic approach:

(a) It cuts teachers off from a reconsideration of their professional practices. In a word, it discourages them to reflect upon their teaching. They have made up their minds; they will use anything that works which can obtain results and is safe from ideological excesses.

(b) Adopting the eclectic approach can be unsafe as a teacher may fall victim of the methodological baggage that comes with it. 
(c) Mixing all manner of methods and approaches may result in gathering in one's teaching arsenal; but using such a mixed bag can lead to all kinds of conflicts.

(d)When introduced to new methods and techniques, teachers, in their haste to integrate these into their traditional styles of teaching forget about the rationale for the techniques altogether.

(e) If an innovative technique is used only occasionally, and mixed in with other (potentially contradictory ones), the effect of the new is diluted.

Although there are a number of known weaknesses of the eclectic approach, the approach is more advantageous than disadvantageous. In fact, most of the weaknesses mentioned above are only justifiable when teachers are poorly trained and prepared for the classroom. Weidmann (2001:6) is possibly right when he states that "the argument that emerges [against eclecticism] is perhaps more about the dangers of an unprincipled eclecticism than anything else". This is the reason why Eclecticism requires teachers who know their learners, subject content, methods of teaching and what teaching is all about. They need to understand what eclecticism means and be able to give reasons for any choice of the technique or methods they integrate.

\section{Misconceptions of the EClectic ApProach to Language Teaching}

In the next section, an attempt is made to show and discuss three major misconceptions about the eclectic approach. To arrive at the data, interviews with 90 teachers of English from 9 different secondary schools within central province of Zambia were interviewed. They were asked to explain how they understood the eclectic approach. While some teachers showed 'correct' understanding of the approach, others did not which is what informs this paper. The first misconception was that teachers understood the eclectic approach as the use of several methods within the lesson one after the other. The following is what they said:

It is mixed and it is based on the learners and it allows the learner to practice and you can easily see if the learner has grasped what he or she has been learning. So, you try to use different methods until the learners understand the topic.

The eclectic approach is using different methods. If you use this method and it doesn't work, you try another one. If it fails, you try another one, just like that. It is good because some learners don't understand easily.

The two responses above view eclecticism as the use of many isolated methods. The respondents believed that using the eclectic approach means starting with one method, and if it fails, the teacher should resort to another one until s/he finds one which works. Thus, while they appear to understand what the eclectic approach by calling it 'mixed method' or using different methods', they held a misconception on how it should be realised in the classroom. This is evident from their arguments that a teacher should continue using different methods until s/he finds one which works. Clearly, it shows that they misunderstood the meaning of the eclectic approach and how it should be applied in the classroom. In fact, viewing the eclectic approach as being the use of several methods one after the other results into a single method. The only difference is that one will use several single methods. On the contrary, the eclectic approach is and should be viewed as one approach except that it embraces characteristics of more than one method. Thus, embracing features of more than one method does not mean that using the eclectic method is using several isolated methods.

The second misconception is that the eclectic approach can only work if pupils are fluent in the target language. They mentioned pupils' poor language background as an inhibitor to the use of the eclectic approach, and Respondents explained that some pupils could not speak English, and this problem was worse in rural areas than in urban areas. Teachers added that most pupils especially in rural areas came from uneducated parents who could not speak English. Most of them came from communities where the dominant language of communication was an indigenous Zambian language, such as Nyanja, Bemba, Lenje and Tonga. Thus, most pupils were more familiar with their home language than with English. Such pupils spoke their home languages even when they went to school. Respondents stated that when such pupils were asked to speak English, they resorted to keeping quiet since they could not express themselves in English. According to the respondents, this lack of English proficiency meant that they could not use the communicative activities (which characterise the eclectic approach) since pupils would not participate. Some teachers explained that this was mostly the reason why they avoided the eclectic approach since pupils could not participate in classroom interaction through the English medium. 
Here are some of the responses recorded:

Some pupils are not grounded in English. We receive pupils from different places. Some pupils do not know how to read. Others, writing is a problem. Some can't even understand (English). So, this (using the eclectic approach) is difficulty.

The problem here is that pupils speak Nyanja and Bemba. Some speak Lenje and Tonga even at school. They don't speak English. You ask them to speak English, they are quiet. So, how can you use the eclectic method? They can't communicate. They like the local language. So, we teach and develop headache, but they don't still understand. We have pupils in grade 11 who cannot read.

You see, that's why for me, I use the lecture method. These pupils they don't understand English. Maybe, those in Lusaka. But here, it's not possible. And this is a farming area, so, their exposure to English is limited. It's not possible to use the method (eclectic) you are talking about.

It is evident from the responses above that, in the opinion of these teachers, a lack of fluency in English hindered some pupils from classroom participation thereby making the eclectic approach challenging and sometimes impossible to use. Put differently, it can be asserted that the language background of the pupils was a factor in the implementation of the eclectic approach where good learners' English background meant teachers could easily use the approach while learners' weak English background made the approach difficult and sometimes impossible to use.

The findings above have shown that teachers of English misunderstood the meaning and the practical implications of the eclectic approach. As noted earlier, the eclectic approach allows the use of L1 or a second language acquired earlier to be used in the classroom as a resource to access learning. Thus, to suggest that one cannot use the eclectic approach if learners were not fluent in the target language shows not only the misconception teachers held about the eclectic approach but also the negative attitudes they held about local languages relative to English. As noted from the responses, Zambian languages and any other languages and varieties besides English were not allowed to be used in the classroom. This attitude and practice is at variance with the notions of vertical and horizontal discourses to teaching. According to Bernstein (1999), vertical discourses are defined as officially recognised knowledge and policies emanating from the state via its Department of Education, while horizontal discourses are the unofficial ones largely shared by teachers, parents and learners. In the context of this study, the formal variety of English as recommended by the syllabus falls under the vertical discourse. On the other hand, Zambian languages and any other language variety fall under the horizontal discourse. Thus, Zambian languages form part of the learners' background which a teacher need to consider when preparing the lesson as well as when teaching. Thus, the vertical and horizontal discourses should work hand in hand to enhance learning achievement by the pupil (Haugen (2009). Infact, this is part of what Wali (2009), Gao (2011), Kumaravadivelu (2006), Brown (2002) and Ali (1981) meant when they noted that the eclectic approach is context sensitive and it recognises the background of the learner. In this case, Zambian languages and any other language variety become stepping stones or resources which pupils and teachers will use to access English. This could involve what is called translanguaging, which in its original conceptualisation is defined as "the purposeful pedagogical alternation of languages in spoken and written, receptive and productive modes" (Hornberger and Link 2012: 262, see also Baker 2001, 2003; Williams 1994). According to Lasagabaster and Garcia (2014:557), translanguaging "fosters the dynamic and integrative use of bilingual students' languages in order to create a space in which the incorporation of both languages is seen as natural and teachers accept as a legitimate pedagogical practice". The basic tenet of translanguaging as a classroom practice is to engender multilingual and multimodal literacies. As Garcia (2009: 44) notes, translanguaging is about "engaging in bilingual or multilingual discourse practices [and] not on languages as has often been the case, but on the practices of bilinguals that are readily observable."

One question that comes to mind is whether translanguaging is not a different reincarnation of codeswitching. In justifying why translanguaging should be seen as a new approach, Hornberger and Link (2012: 263) contend that research on code-switching "tended to focus on issues of language interference, transfer or borrowing" while "translanguaging "shifts the lens from cross-linguistic influence' to how multilinguals 'intermingle linguistic features that have hereto been administratively 
or linguistically assigned to a particular language or language variety' (Garcia 2009: 51)." In addition, translanguaging is multimodal in that it transcends verbal communication (both spoken and written language) to other mediated and mediatized modes and related literacies pupils bring to the classroom. Zambian children, even those in rural areas have been exposed or are incrementally being introduced to many forms of languages and new technologies such as cell phones and other computerised gadgetry. Following Banda (2010) and Blackledge and Creese (2010), alternative bilingual models of classroom practice such as translanguaging can help the learners of English and teachers alike to mitigate and counteract the negative effects of monolingual language ideologies and policies as well as to bridge home and school multilingual literacy practices and identities. This is so because "translanguaging as a pedagogy has the potential to liberate the voices of language minoritised students" (Creese and Blackledge, 2015:26, see also Garcia, 2014). This forms part of what defines the eclectic approach. Thus, adopting monolingual ideologies in a multilingual classroom shows lack of understanding and appreciation of the eclectic approach.

The third misconception held by respondents was that the eclectic approach was time consuming and therefore difficult or impossible to use. Some respondents stated that the eclectic approach was time consuming as well as confusing to learners. They added that it was too demanding on the part of the teacher as it involved the use of several classroom activities in the classroom. Furthermore, teachers explained that the approach was also confusing especially to slow learners. They explained that learners easily understood concepts when a teacher only used a single method. However, if a teacher switched to another method or change from one activity to another within the same lesson, learners would think that the teacher was introducing a different concept and they would get confused and fail to follow the lesson. For this reason, they stated that a single method with the use of one activity was more straightforward and helped the learners to follow the lesson better than the eclectic method which calls for the use of various activities within one lessons ( See Li 2012). Consider the following responses:

R11: The eclectic approach is time consuming. Sometimes, you can plan a lesson. After all those activities, it will be time up. Then, you can't give an exercise. Then, you want to postpone the lesson to the next period. So, it takes too much time. If you involve learners, the lesson will take many weeks. Maybe in Lusaka, learners can help. But here in rural areas, they can't learn.

R12: It is also confusing especially to slow learners. If you explain something in a different way, a slow learner will think that it is a different thing altogether. So, as a teacher, you end up misleading the learners. So, we don't use it. We put it in the lesson but it's just for supervisors. But we use what works for learners. So, we use the lecture method. Because the people who check the file expect the eclectic approach, so, we put it there in the lesson plan, so we write it just on paper. In remedial work, that's where we use another method".

The eclectic method, as previously noted, involves a variety of classroom activities (cf LarsenFreeman, 2000; Ali, 1981) and it is learner centred (cf. Gao 2011) which means that learners should be the focal point of the lesson (cf. Wali 2009). However, as seen from the above two findings, teachers find the approach time consuming, too involving and not suitable for some learners. For these reasons, they felt that a single method approach was better than the eclectic approach. These findings signal lack of practical knowledge of the eclectic method on the part of teachers and such a misconception also implies that some teachers did not apply the approach correctly and or appropriately. From the two responses above, one can see the first misconception also coming out where some teachers explained that the eclectic approach is using different isolated methods within one method. In fact, it is this misconception which leads to another misconception that the eclectic approach is confusing. The confusion obviously comes from the wrong application of the approach. The misconception also leads to lack of judicious management of time since teachers use different methods instead of using the eclectic as one approach which is realised through several classroom activities.

\section{Summary}

In summary, the paper has made an attempt to present and discuss the conceptualisation of the eclectic approach by bringing out its major features. The paper has shown the view of language and language teaching under the eclectic approach. The second part of the paper has brought out three major 
misconceptions held by selected teachers of English in Zambia about the eclectic approach. They viewed it as using several isolated methods in the same lesson. They also believed that the eclectic approach only works if learners are fluent in the target language and finally, they argued that the eclectic approach was confusing and time consuming. These misconceptions have been discussed and reasons have been given why they are misunderstanding of what the approach really means. Thus, there is need for teacher educators and language teachers to reflect on their conceptualisations so that we avoid the challenges faced by teachers of language in schools.

\section{REFERENCES}

Ali, A.M. (1981). Teaching English to Arab Students. Jordan: Al-Falah House.

AL- Hamash I. K. and Younis, H. (1985). Principles and Techniques of Teaching English as a second language. Bagdad: Alshaay Press.

Allwright, R. L.(2000). Exploratory Practice: An "appropriate methodology"for Language Teacher Development. In 8th IALS Symposium for Language Teacher Educators, Edinburgh, Scotland.

Baker, C. (2003). Biliteracy and Transliteracy in Wales: Language Planning and the Welsh National Curriculum. In N.H. Hornberger (ed.), Continua of Biliteracy: An Ecological Framework for educational Policy, Research and Practice in Multilingal Settings. Clevedon: Multilingual Matters, 71-90.

Baker, C. (2011). Foundations of Bilingual Education and Bilingualism. Clevedon: Multilingual Matters.

Banda, F. (2010). Defying Monolingual Education: Alternative Bilingual Discourse Practices in Selected Coloured Schools in Cape Town. Journal of Multilingual and Multicultural Development, 31(3): 221-235.

Banda, D. (2011). The Situational Approach to Language Teaching. Unpublished LSE 332 Lecture Notes. The University of Zambia.

Bernstein, B. (1999). Vertical and Horizontal Discourse: An Essay. British Journal of Sociology of Education, 20(2): 157-173.

Blackledge, A. and Creese, A.(2010). Multilingualism: A Critical Perspective. London: Continuum International Publishing Group.

Bock, Z (2014). Approaches to Communication. In Bock, Z. and Mheta G. (eds) Language, Society and Communication. Pretoria: Van Schaik Publishers. Pp 35-54.

Brown, H.D. (2002). English Language Teaching in the 'Post-Method' Era: Toward better Diagnosis, Treatment, and Assessment. In J. Richards and W. Renandya (eds.), Methodology in Language Teaching: An Anthology of Current Practice. Cambridge: Cambridge University Press, 9-18.

Brown, H. D. (1994). Teaching by Principles. Englewood Cliffs, NJ: Prentice Hall.

Creese, A., and Blackledge, A. (2010). Translanguaging in a Bilingual Classroom: A Pedagogy for Learning and Teaching? Modern Language Journal, 94 (1):103-113.

Creese, A., and Blackledge, A.(2014). Researching Bilingual and Multilingual Education. The Hand book of Bilingual and Multilingual Education.

Creese, A. and Blackledge, A. (2015). Translanguaging and Identity in Educational Settings. Annual Review of Applied Linguistics, 35 (2015): 20-35.

Curriculum Development Centre.(2013). Senior Secondary School English Language Syllabus. Lusaka: CDC.

uncum, P. (2004). Visual Culture isn't just Visual: Multiliteracy, Multimodality and Meaning. Studies in Art education,252-264.

Garcia, O. (2009). Bilingual Education in the 21st Century: A Global Perspective. Malden, MA: Wiley-Blackwell.

Garcia, O. and Sylvan, C. (2011). Pedagogies and Practices in Multilingual Classrooms: Singularities in Pluralities. The Modern Language Journal, 95 (3): 385-400.

García, O., and Wei, L. (2014). Translanguaging: Language, Bilingualism and Education. London: Palgrave Macmillan. 
García, O. and Velasco, P. (2014). Translanguaging and the Writing of Bilingual Learners, Bilingual Res- earch Journal: The Journal of the National Association for Bilingual Education, 37:1, 6-23, DOI: $10.1080 / 15235882.2014 .893270$

Gao, L. (2011). Eclecticism or Principled Eclecticism. Creative Education. 2(4): 363-369.

Gebhard, J. G., Gaitan,S.,\& Oprandy, R. (1990). Beyond Prescription: The Student Teacher as Investigator. In J. C. Richards \& D. Nunan (Eds.), Second Language Teacher Education (pp. 1625). Cambridge: Cambridge University Press.

Gilliland, B. E., James, R. K., \& Bowman, J. T (1994). Response to the Lazarus and Beutler's Article “On Technical Eclecticism." Journal of Counseling and Development, 72, 554-555.

Halliday, M. A. K. (1978). Language as Social Semiotic. London: Edward Arnold.

Haugen, C.R.(2009).Recontextualisations of Trainability: Learning Strategies and Social Background. In Contextualizations and Recontextualizations of Discourses on Equity in Education (pp. 143-167). PhD Thesis. Trandheim: Norwegian University of Science and Technology.

Hornberger, N.H. and Link H. (2012) Translanguaging and Transnational Literacies in Multilingual Classrooms: A Biliteracy Lens. International Journal of Bilingual Education and Bilingualism, 15(3): 261-278, DOI: 10.1080/13670050.2012.658016.

Hymes, D. (1971). Pidginization and Creolization of Language. Cambridge: C.U.P.

Hymes, D. (1972). On Communicative Competence. In J.B. Pride and J.Holmes (eds), Sociolinguistics. Harmondsworth: Penguin. 269-293.

Iedema, R. (2003). Multimodality, Resemiotization: Extending the Analysis of Discourse as Multisemiotic Practice. Visual Communication, 2(1): 29-57.

Jewitt, C. (2005). Multimodality, "Reading", and "Writing" for the 21st Century. Discourse: Studies in the Cultural Politics of Education, 26(3): 315-331.

Krashen, S. (1982). Principles and Practice in Second Language Acquisition. Oxford: Pergamon.

Kumar, C.P. (2013). The Eclectic Method: Theory and Its Application to the Learning of English. International Journal of Scientific and Research Publications, 3(6).ISSN 2250-3553.

Kumaravadivelu, B. (2001). Toward a Postmethod Pedagogy. TESOL Quarterly, 35:537-560. doi:10. $2307 / 3588427$.

Kumaravadivelu, B. (2006). Understanding Language Teaching: From Method to Post method. Mahwh, NJ: Lawrence Erlbaum Associates.

Larsen-Freeman, D and Long, M. (1991). An Introduction to Second Language Research. London: Longman.

Larsen-Freeman, D. (1992). A Non Hierarchical Relationship between Grammar and Communication, Part 1. In. J.E. Alids (ed). George Town University Round Table on Language and Linguistics, pp.158-165. Washington DC: George Town University Press.

Larsen-Freeman, D. (2000). Techniques and Principles in Language Teaching (2nd ed.). Oxford: Oxford University Press.

.Larsen-Freeman, D. (2001). Teacher Learning and Learner Learning in TESOL. TESOL Quartery, 35 (4):608-629.

Lasagbaster, D. and Ofelia, G. (2014). Translanguaging: Towards a Dynamic Model of Bilingualism at School / Translanguaging: hacia un modelo dinámico de bilingüismo en la escuela. Culture and Education, 26(3): 557-572.

Lewis, G., Jones, B., and Baker, C. (2012). Translanguaging: Developing its Conceptualisation and Contextualisation. Educational Research and Evaluation, 18(7): 655-670.

Li, W. (2012). An Eclectic Method of College English Teaching. Journal of Language Teaching and Research, 3 (1): 166-171.

Mart, C.T.(2013). The Grammar-Translation Method and the Use of Translation to Facilitate Learning in ESL Classes. Journal of Advances in English Language Teaching. 1(4): 103-105.

Mellow, J.D. (2000). An Examination of Western Influences on Indigenous Language Teaching. ERIC.

Mellow, J.D (2002) Towards Principled Eclecticism in Language Teaching: The Two Dimensional Model and Centring Principle. Teaching English as a Second Language Journal, 5 (4): A-1. 
Nunan, D. (2001). Tradition and Change in the ELT Curriculum. Plenary Presentation at the Third International Symposium on ELT in China, Beijing, China.

Qing-xue, L and Fang, S.J. (2007). An Analysis of Language Teaching Approaches and Methods Effectiveness and Weakness. US-China Education Review, 4(1): 69

Richards, J.C. and Rodgers, T.S. (2001). Approaches and Methods in Language Teaching (2nd Ed.). Cambridge: Cambridge University Press.

Ridge, E. (2000). Beyond Mere Communication. Per Linguam, 16(2):46-56. doi.org/10.5785/16-2139.

Savignon, S.J.(2002).Communicative Language Teaching: Linguistic Theory and Classroom Practice. In Savignon, S.J.(ed). Interpreting Communicative Language Teaching. New Haven: Yale University Press. 1-27.

Skehan, P. (1998). A Cognitive Approach to Language Teaching. Oxford: Oxford University Press.

Stern, H. H. (1992). Issues and Options in Language Teaching. Oxford: Oxford University Press.

Wali, N.H. (2009). Eclecticism and Language Learning. Al- Fatih Journal. No .39. Diyala University College of Basic Education.

Weideman, A. (2001).The Old and the New: Reconsidering Eclecticism in Language Teaching. Linguam, 17(1):1-13. doi.org/10.5785/17-1-131.

Williams, C. (1994). Arfarniad o ddulliau dysgu ac addysgu yng nghyd-destun addysg uwchradd ddwyieithog [Evaluation of Teaching and Learning Methods in the Context of Bilingual Secondary Education]. Bangor: University of Wales.

Zainuddin, H., Yahya, N., Morales-Jones, C.A. and Ariza, E.N.W. (2011). Fundamentals of Teaching English to Speakers of Other Languages in K-12 Mainstream Classrooms. Debuque: Kendallhunt Publishing Company.

\section{AUTHOR's BIOGRAPHY}

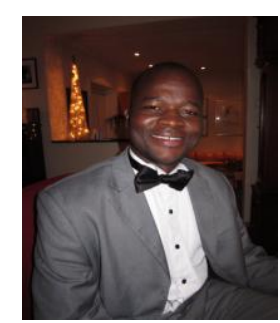

Dr. David Sani Mwanza, is a Teacher Educator at the University of Zambia in the Department of Language and Social Sciences Education. He Holds a PhD in Linguistics from the University of Western Cape, South Africa. His research interests and areas of postgraduate supervision include Teacher Education, Language Teaching theory and Practice, Multilingual Education/Literacy and Language in Education Policy. 